\title{
PENGARUH ENDORPHINE MASSAGE TERHADAP SKALA INTENSITAS NYERI KALA I FASE AKTIF PERSALINAN
}

\author{
$\underline{\text { Antik }^{1)} \text { Arum Lusiana }}{ }^{2)}$ Esti Handayani ${ }^{3)}$
}

Email: arum.lusiana@gmail.com

\begin{abstract}
Labor pain as a contraction of the myometrium, is a physiological process with a different intensity on each individual. Pain arising in childbirth cause great concern and usually creates fear and stress. Pain management method of the first stage of labor was known two types, it is pharmacological management and non-pharmacological. One way of the non-pharmacological management to decrease the labor pain is endorphine massage. The purpose of this research was to determine the effect of edorphine massage to decrease the pain intensity scale of the first stage of the active phase of labor.

This research method using Quasi experimental designs One Group Pre-test Post-test. The sample in this study were 30 respondents primigravid maternal in the region of Tembarak Temanggung health centers was selected using purposive sampling techniques, and using Wilcoxon test to analysis.

In this study 23 respondents showed a better response to a pain scale of the first stage of labor after endorphine massage. While seven other respondents showed no change after being given endorphine massage treatmen. Based on the research results obtained using the Wilcoxon statistical test significance value ( $\mathrm{p}$ value) of 0.000 . It can be concluded that the hypothesis is accepted, there are effect of endorphin massage decline pain intensity scale of the first stage of the active phase of labor.

From the results of the study are expected health workers, especially midwives in its role to empower the family in reducing labor pain by conducting socialization in the family and the husband of endorphin massage during a class of pregnant women or antenatal care so that when labor was accompanied by family, especially her husband.
\end{abstract}

Keyword : endorphine massage, labour pain, pain scale

1) Student of Diploma Programme Midwifery Magelang

2) ${ }^{3)}$ Lecture of Diploma Programme Midwifery Magelang

Rasa nyeri muncul akibat respon psikis dan refleks fisik. Rasa nyeri dalam persalinan menimbulkan gejala yang mudah dikenali. Peningkatan aktivitas sistem saraf simpatik timbul sebagai respon terhadap nyeri dan dapat mengakibatkan perubahan tekanan darah, denyut nadi, pernafasan, dan warna kulit. Perubahan afektif berupa rasa cemas disertai lapang perseptual yang menyempit, mengerang, menangis, gerakan tangan (yang menandakan rasa nyeri) dan ketegangan otot yang sangat di seluruh tubuh (Bobak dkk, 2004).

Nyeri yang dirasakan pada kala I persalinan menurut Maryunani (2010), bersifat sakit dan tidak nyaman pada fase akselerasi, nyeri dirasakan agak menusuk pada fase dilatasi maksimal, dan nyeri menjadi lebih hebat, menusuk, dan kaku pada fase deselerasi. Andarmoyo dan Suharti (2013) mengatakan bahwa nyeri persalinan sebagai kontraksi miometrium, merupakan proses fisiologis dengan 
intensitas yang berbeda pada masingmasing individu.

Metode penanganan nyeri kala I persalinan dikenal 2 jenis, yaitu penanganan nyeri secara farmakologis (menggunakan obat-obatan) dan penanganan nyeri secara non-farmakologis (tanpa obatobatan). Salah satu cara penatalaksanaan nonfarmakologis untuk mengurangi rasa nyeri persalinan dengan endorphine massage. Endorphine massage merupakan sebuah terapi sentuhan atau pijatan ringan yang diberikan pada wanita hamil menjelang persalinan.

Hasil survai pendahuluan di wilayah kerja Puskesmas Tembarak Temanggung bahwa telah dilakukan wawancara dan pengamatan dari 5 ibu bersalin di wilayah kerja Puskesmas Tembarak Temanggung didapatkan hasil ibu primipara merasakan nyeri yang hebat pada kala I persalinan terutama pada fase aktif. Ibu sering kali merasa cemas, bingung dan khawatir pada proses persalinan sehingga menyebabkan nyeri smakin terasa bertambah, bahkan dua dari lima ibu primipara yang diamati menyatakan tidak tahan pada sakit yang dirasakan.

Perlakuan endorphin massageakan dilakukan pada saat fase aktif persalinan mengingat nyeri pada kala ini bersifat intermitten. Tindakan ini juga diharapkan agar ibu merasa nyaman serta dapat mengontrol emosinya untuk tetap tenang selama persalinan agar tidak menambah rasa nyeri yang dirasakan oleh ibu..Tujuan penelitian ini adalah untuk mengetahui pengaruh endorphinemassage terhadap skala intensitas nyeri kala I fase aktif persalinan.

\section{METODE PENELITIAN}

Penelitian ini menggunakan metode Quasi Eksperimentdengan desain One
Group Pre-test Post-test. Tempat penelitian adalah di wilayah kerja puskesmas Tembarak Temanggung yang dilakukan pada bulan Mei 2016. Populasi dalam penelitian ini adalah semua ibu primigravida yang berada dalam kala I fase aktif persalinan normal yang berada di wilayah kerja Puskesmas Tembarak Temanggung dengan besarsampel 30 responden yang dihitung dengan rumus slovin. Teknik pengambilan sampel dengan menggunakan teknik purposive sampel.

Instrumen penelitian menggunakan lembar observasiyang berisi tentang skala intensitas nyeri kala I persalinan sebelum diberikan perlakuan (endorphine massage) dan sesudah diberikan perlakuan (endorphine massage) yang dialami oleh responden dengan menggunakan skala bourbanis.

Data yang diperoleh diolah secara komputerisasi dan dianalisis dengan uji statistik wilcoxon untuk mengetahui pengaruhendorphine massage terhadap skala intensitas nyeri kala I fase aktif persalinan.

\section{HASIL PENELITIAN}

Berdasarkan hasil penelitian yang dilakukan pada 30 responden ibu bersalin, didapatkan skala nyeri kala I persalinan sebelum diberikan perlakuan endorphin massage seperti ditampilkan dalam tabel berikut :

Tabel 4.1Distribusi Frekuensi Skala Nyeri Kala I Persalinan sebelum diberikan perlakuan endorphin massage

\begin{tabular}{lll}
\hline $\begin{array}{l}\text { Kriteria } \\
\text { Nyeri }\end{array}$ & $\begin{array}{l}\text { Frekuensi } \\
\text { (orang) }\end{array}$ & $\begin{array}{l}\text { Persentase } \\
(\%)\end{array}$ \\
Tidak Nyeri & - & - \\
Nyeri Ringan & 1 & 3,33 \\
Nyeri Sedang & 11 & 36,67 \\
Nyeri Berat & 13 & 43,33 \\
Nyeri Sangat & 5 & 16,67 \\
\hline
\end{tabular}


Berat

Total

30

100

Dari data tabel 4.1 disimpulkan bahwa semua responden mengalami nyeri dan kriteria terbanyak adalah responden yang mengalami nyeri berat yaitu sebanyak 13 responden $(43,33 \%)$

Skala nyeri kala I persalinan setelah diberikan perlakuan endorphin massage

Tabel 4.2Distribusi Frekuensi Skala Nyeri Kala I Persalinan sesudahdiberikan perlakuanendorphin massage

\begin{tabular}{lcc}
\hline $\begin{array}{l}\text { Kriteria } \\
\text { Nyeri }\end{array}$ & $\begin{array}{l}\text { Frekuensi } \\
\text { (orang) }\end{array}$ & $\begin{array}{l}\text { Persentase } \\
(\%)\end{array}$ \\
\hline Tidak Nyeri & - & - \\
Nyeri Ringan & 11 & $36,7 \%$ \\
Nyeri Sedang & 13 & $43,3 \%$ \\
Nyeri Berat & 6 & $20 \%$ \\
Nyeri Sangat Berat & - & \\
\hline Total & 30 & 100 \\
\hline
\end{tabular}

Sumber :data primer

Berdasarkan data diatas didapatkan hasil yaitu kriteria nyeri sangat berat sudah tidak ditemukan, sedangkan responden terbanyak ditemukan padakriteria nyeri sedang yaitu sejumlah 13 responden $(43,33 \%)$.

Skala nyeri kala I persalinan sebelum dan setelah dilakukan endorphin massage

Tabel 4.3 Distribusi Frekuensi SkalaNyeri Kala I Persalinan sebelum dan sesudah diberikan perlakuanendorphin massage

\begin{tabular}{lcccc}
\hline \multirow{2}{*}{$\begin{array}{c}\text { skala } \\
\text { nyeri }\end{array}$} & \multicolumn{2}{c}{ Sebelum } & \multicolumn{2}{c}{ Sesudah } \\
\cline { 2 - 5 } & Orang & $\%$ & Orang & $\%$ \\
\hline $\begin{array}{l}\text { Tidak } \\
\text { nyeri }\end{array}$ & - & - & - & - \\
\hline $\begin{array}{l}\text { Nyeri } \\
\text { ringan }\end{array}$ & 1 & 3,33 & 11 & 36,7 \\
\hline $\begin{array}{l}\text { Nyeri } \\
\text { sedang }\end{array}$ & 11 & 36,67 & 13 & 43,3 \\
\hline $\begin{array}{l}\text { Nyeri } \\
\text { berat }\end{array}$ & 13 & 43,33 & 6 & 20 \\
\hline $\begin{array}{l}\text { Nyeri } \\
\text { sangat } \\
\text { berat }\end{array}$ & 5 & 16,67 & - & \\
\hline Jumlah & 30 & 100 & 30 & 100 \\
\hline Sumber: & parmy & & & \\
\hline
\end{tabular}

Sumber: data primer
Berdasarkan data diatas didapatkan kriteria skala nyeri kala I persalinan setelah diberikan endorphin massage terdapat perubahan skala nyeri, yaitu pada nyeri ringan didapatkan kenaikan dari yang hanya 1 responden $(3,33 \%)$ menjadi 11 responden (36,7\%), pada nyeri berat terdapat 13 responden $(43,33 \%)$ menjadi hanya 6 responden (20\%), Sedangkan responden dengan kriteria nyeri sangat berat sudah tidak ditemukan lagi setelah diberikan perlakuanendorphin massage pada kala I persalinan.

Tabel 4.4 pengaruh endorphin massage terhadap nyeri kala I fase aktif persalinan

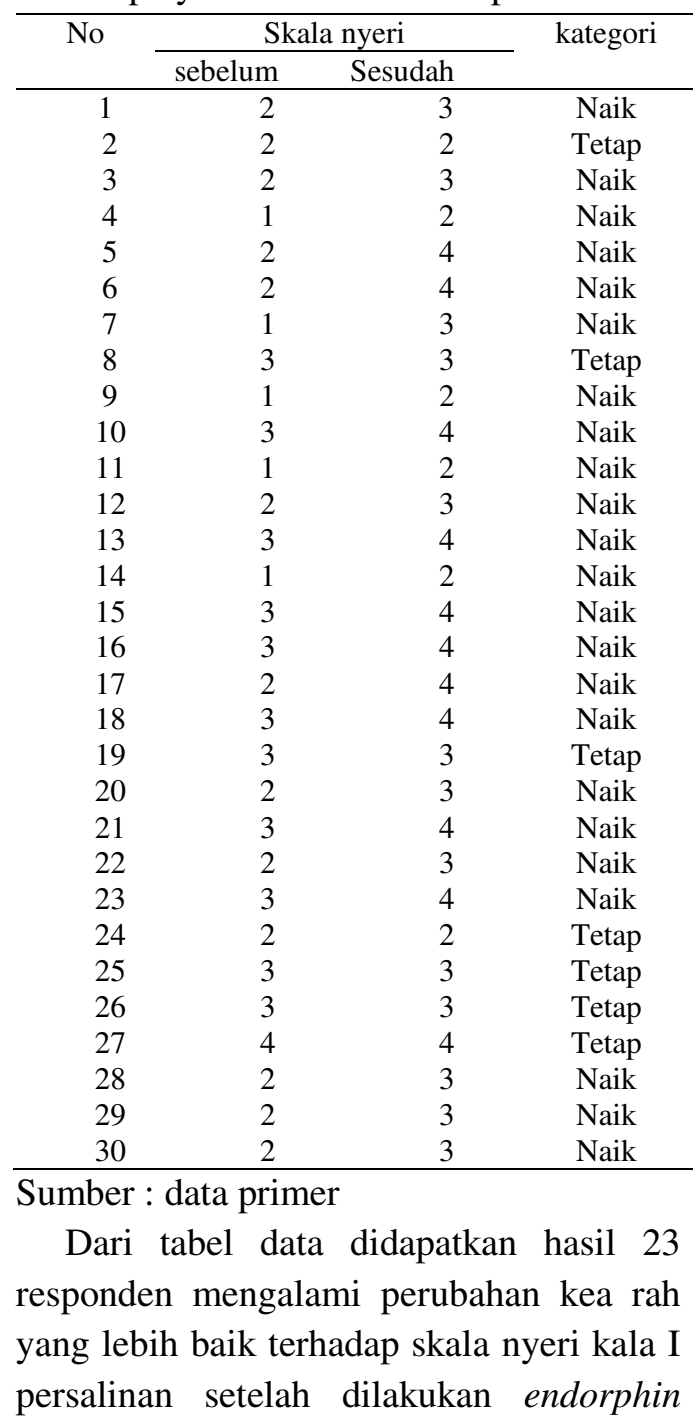


massage.Sedangkan 7 responden lain tidak mengalami perubahan.

Tabel 4.5 Tabulasi hasil olah data

\begin{tabular}{ccc}
\hline Kategori & $\begin{array}{c}\text { Positi } \\
\text { ve Rank }\end{array}$ & $\begin{array}{r}\mathrm{P} \\
\text { value }\end{array}$ \\
\hline Nyeri Sebelum & & 0,0 \\
dan Sesudah & 23 & 00 \\
Perlakuan & &
\end{tabular}

Pada tabel hasil statistik didapatkan positif rank sebanyak 23, artinya ada23 responden menunjukkan respon yang lebih baik terhadap skala nyeri kala I persalinan setelah dilakukan endorphin massage. Berdasarkan hasil uji statistik menggunakan komputerisasi dengan uji komparatif wilcoxon didapatkan nilai signifikasi (p value) sebesar 0,000. Dengan tingkat kepercayaan $95 \%$, jika nilai $\mathrm{p}<0,05$ maka Ha diterima. Sehingga dapat disimpulkan bahwa hipotesis penelitian diterima, yaitu ad apengaruh endorphin massageterhadap skala intensitasnyerikala I fase aktif persalinan.

\section{PEMBAHASAN}

Skala nyeri kala I persalinan sebelum dilakukan endorphinmassage Pada penelitian yang telah dilakukan menunjukkan hasil kriteria terbanyak didapatkan pada nyeri berat yaitu sejumlah 13 responden dan terdapat kriteria nyeri sangat berat yaitu 5 responden.Hal ini membuktikan bahwa setiap persalinan mengalami nyeri.Nyeri persalinan juga merupakan proses fisiologis dengan intensitas yang berbeda-beda pada masing-masing individu (Cuningham, 2004).

Pada penelitian ini semua responden mengalami nyeri karena terdapat banyak faktor yang dapat mempengaruhi nyeri, salah satunya dikarenakan semua responden belum memiliki pengalaman persalinan.
Skala nyeri kala I persalinan umumnya dapat diukur dengan berbagai macam cara diantaranya dengan observasi yang dilakukan oleh enumerator untuk menggambarkan nyeri sesuai dengan ketentuan skala yang akan diukur. Skor/nilai skala nyeri dapat dicatat pada flow chart untuk memberikan pengkajian nyeri yang berkelanjutan.Pengukuran nyeri sangat subjektif dan individual. Selain itu, kemungkinan nyeri dalam intensitas yang sama dirasakan sangat berbeda oleh dua orang yang berbeda. Pengukuran nyeri dengan pendekatan objektif yang paling mungkin adalah menggunakan respon fisiologi tubuh terhadap nyeri itu sendiri (Andarmoyo dan Suharti, 2013).

Skala nyeri kala I persalinan setelah dilakukan endorphin massage. Hasil penetilian setelah dilakukan endorphin massagedidapatkan hasil yaitu responden terbanyak ditemukan pada kriteria nyeri sedang dengan jumlah 13 responden $(43,33 \%)$. Menurut peneliti, hal ini dapat terjadi karena hormon edorphine telah bekerja ketika diberikan perlakuan endorphin masage.Responden yang diberikan perlakuan endorphin massageakan mengalami relaksasi dikarenakan keluar nya hormon endorphin. Endorphinsendiri merupakan polipeptida yang terdiri dari 30 unit asam amino.Opioid-opioid hormonhormon penghilang stres, seperti kortikotrofin, kortisol, dan kotekolamin (adrenalin- noradrenalin) yang dihasilkan tubuh untuk mengurangi stres dan menghilangkan rasa nyeri (Aprilia dan Ritchmon, 2011).Selain itu, endorphin juga dapat meningkatkan sistem kekebalan tubuh/imunitas, mengurangi rasa sakit, mengurangi stres, dan memperlambat proses penuaan (Aprilia, 2010).

Pada penelitian ini endorphin masage dilakukan dengan cara memberikan 
sentuhan berupa pijatan lembut dan ringan arah bahu kiri dan kanan membentuk huruf $\mathrm{V}$, ke arah tulang ekor dan dilakukan berkali-kali ketika terjadi kontraksi pada saat persalinan.

Pengaruhendorphin massage terhadap intensitas skala nyeri kala I fase aktif persalinan. Berdasarkan hasil uji statistik menggunakan uji komparatif wilcoxon didapatkan nilai signifikasi ( $\mathrm{p}$ value) sebesar 0,000.Dengan tingkat kepercayaan $95 \%$, jika nilai $\mathrm{p}<0,05$ maka Ho ditolak dan Ha diterima. Jadi hipotesis penelitian diterima bahwa ada pengaruh penggunaan endorphin massage terhadap skala intensitas nyeri kala I fase aktif persalinan.

Pada tabel hasil uji statistic, 23 responden menunjukkan respon yang lebih baik terhadap skala nyeri kala I persalinan setelah dilakukan endorphin massage. Sedangkan 7 responden lain menunjukkan tidak ada perubahan. Pada 23 responden yang mengalami perubahan ke arah yang lebih baik ini membuktikan bahwa endorphin massage adalah metode yang efektif untuk mengurangi nyeri pada kala I persalinan. Pada 7 responden yang tidak mengalami perubahan skala nyeri ini dapat terjadi karena ada faktor subyektifitas dalam perlakuan endorphin massage karena rasa takut dan cemas yang berlebihan akan memengaruhi rasa nyeri persalinan. Setiap ibumempunyai persepsi sendiri-sendiri tentang nyeri persalinan danmelahirkan.Hal ini karena ambang batas rangsang nyeri setiap orang berlainan dan sangat subjektif (Andarmoyo dan Suharti, 2013).

Selain itu, pada tabel hasil uji statistik juga didapatkan perubahan dari yang sebelum diberikan perlakuan endoprhine massagerata-rata terdapat nyeri berat berubah menjadi rata-rata nyeri sedang setelah diberikan perlakuan endorphin massage.

Menurut hasil penelitian dengan menggunakan uji Wilcoxon didapatkan kesimpulan terdapat ada pengaruh penggunaan endorphin massage terhadap skala intensitas nyeri kala I fase aktif persalinan.

\section{SIMPULAN}

Dari penelitian yang telah dilakukan oleh peneliti ini dapat disimpulkan bahwaendorphin massage merupakan cara yang efektif dalam mengurangi nyeri pada kala I fase aktifpersalinan

\section{DAFTAR PUSTAKA}

Andarmoyo, Sulistyo. dan Suharti. 2013. Persalinan tanpa Nyeri Berlebihan. Jakarta : Ar Ruzz Media.

Aprilia, Yesie. 2010. Hipnostetri Rileks, Nyaman, dan Aman Saat Hamil dan Melahirkan. Jakarta : Gagas Media.

Aprilia, Yesie. 2011. Endorphin Massage. Dalam http:///www.bidankita.com//.

Aprilia, Yesie. dan Brenda, Ritchmond. 2011. Gentle Birth. Jakarta : Gramedia Widiasarana Indonesia.

Arikunto, Suharsimi. 2010. Prosedur Penelitian Suatu Pendekatan Praktik. Jakarta : Rineke Cipta.

Azizah, Iin Nur., Melyana N. R., dan Novita N. A. 2011. Pengaruh Endorphin Massage terhadap Internsitas Nyeri Kala I Persalinan Normal Ibu Primipara di BPS $S$ dan B Demak Tahun 2011.Dalam http://repository.usu.ac.id/bitstream/123 456789/19508/4/Chapter\%20II.pdf. 
Bobak, et al. 2004.Buku Ajar Keperawatan Maternitas.Jakarta : EGC.

Dahlan, Sopiyudin, 2012. Statistik untuk Kedokteran dan Kesehatan.Jakarta : Salemba Medika.

Firdayanti.2009. Terapi Nyeri Persalinan Non Farmakologis.Dalam http://ebookily.net/pdf/terapi-nyeripersalinan-non-farmakologis139119538.html.

Judha, Mohamad, dkk. 2012. Teori Pengukuran Nyeri dan Nyeri Persalinan.Yogyakarta : Nuha Medika.

Kartika, Annisa Wuri. 2003. Pengaruh Kompres Dingin terhadap Penurunan Intensitas Nyeri Bendungan Payudara pada Ibu Post Partum di Wilayah Kerja Puskesmas Kecamatan Gending Kabupaten Probolinggo.Dalam http://www.journal.unipdu.ac.id/index.p hp/eduhealth/article/view/298/268.html.

Kozier, Barbana, et al. 2009. Kozier dan Erb Buku Ajar Praktik Keperawatan Klinis Ed 5.Jakarta : EGC.

Kuswandi, Lanny.2011. Keajaiban HypnoBirthing.Jakarta : Pustaka Bunda.

Kusyati, Eni. 2006. Ketrampilan dan Prosedur Laboratorium Keperawatan Dasar. Jakarta : EGC.

Mander, Rosemary. 2004. Nyeri Persalinan. Jakarta : EGC.
Maryunani, Anik. 2010. Nyeri dalam Persalinan Teknik dan Cara Penanganannya. Jakarta : CV. Trans Info Media.

Melyana, et al. Hypnosis, Endorphin Massage, Relaksasi, dan Intensitas Nyeri Kala I Persalinan.Dalam http://www.ejurnal.com/2013/11/metodepengurangan-rasa-nyeri-pada-kala.html.

Mongan, Marry. 2007. Hypno Bhirting The Mongan Method. Jakarta : PT Bhuana Ilmu Populer.

Notoatmojo, Soekidjo. 2010. Metodologi Penelitian Kesehatan. Jakarta : Rineka Cipta.

Prawirohardjo, Sarwono. 2010. Ilmu Kebidanan. Jakarta : P.T. Bina Pustaka Sarwono Prawirohardjo.

Rusdiatin, Ivana Eko. dan Darmasta Maulana. 2007. Pengaruh Pemberian Teknik Akupresur terhadap tingkat Nyeri Persalinan Kala I di Rumah Sakit Rajawali Citra Potorogo Banguntapan. Dalam

Simkin, P dan Ancheta, R. (2005).Buku Saku Persalinan. Jakarta: EGC.

Sugiyono. 2012. Statistika untuk Penelitian.Jakarta : Alfabeta. 


\title{
PENGARUH PEMBERIAN TABLET FE DAN SARI KACANG HIJAU TERHADAP KADAR HEMOGLOBIN PADA IBU HAMIL
}

\author{
Dewi Luh Retnorini ${ }^{1)}$, Sri Widatiningsih ${ }^{2)}$, Masini ${ }^{3)}$ \\ Email : dewiluhretnorini@gmail.com
}

\begin{abstract}
The purpose of this research was to determine the effect of iron tablet and mung green bean ekstract on hemoglobin levels in pregnant women. This research was conducted in Puskesmas Pare Temang-. This study uses a quasiexperimental. This study population is pregnant women TM III in Pare Primary Health Care Temanggung using total sampling technique sampling which are divided into two groups: the intervention group 32 pregnant women and 32 pregnant women control group.

The results showed that there is the effect of iron tablet and mung bean ekstract on hemoglobin levels in pregnant women with a $p$ value of 0.000 . From the results of the study are expected midwife can improve health services, especially for anemia in pregnant women by providing health education to pregnant women about the benefits of mung bean ekstract as a food ingredient that can increase maternal hemoglobin levels and prevent anemia

Keyword : Iron Tablet, Mung Beans Ekstract, Hemoglobin Level, Pregnant Women

1) Student of Diploma Programme Midwifery Magelang

2) ${ }^{3)}$ Lecture of Diploma Programme Midwifery Magelang
\end{abstract}


Anemia defisiensi besi merupakan salah satu gangguan yang paling sering terjadi terutama selama masa kehamilan (Kristiyanasari, 2010). Ibu hamil dinyatakan anemia jika hemoglobin $(\mathrm{Hb})$ < $11 \mathrm{mg} / \mathrm{L}$ (Kemenkes RI, 2015). Kekurangan zat besi sejak sebelum kehamilan bila tidak diatasi dapat mengakibatkan ibu hamil menderita anemia. Kondisi ini dapat meningkatkan risiko kematian pada saat melahirkan, melahirkan bayi dengan berat badan lahir rendah, janin dan ibu mudah terkena infeksi, keguguran, dan meningkatkan risiko bayi lahir prematur (Kemenkes RI, 2015).

Angka kejadian anemia di Indonesia dalam kehamilan cukup tinggi. Berdasarkan hasil Riset Kesehatan Dasar (Riskesdas) tahun 2013, prevalensi anemia pada ibu hamil di Indonesia sebesar $37,1 \%$, sedangkan kejadian anemia pada ibu hamil di Jawa Tengah pada tahun 2013 sebesar $78,9 \%$, angka ini masih lebih tinggi dari angka nasional yaitu $71,2 \%$ (Dinkes Jateng, 2013).

Anemia pada ibu hamil dapat mengakibatkan gangguan tumbuh kembang janin, abortus, partus lama, sepsis puerperalis, kematian ibu dan janin (Cunningham et al., 2005). Anemia pada ibu hamil juga mengakibatkan terjadinya gangguan plasenta seperti hipertropi, kalsifikasi, dan infark, sehingga terjadi gangguan fungsinya. Hal ini dapat mengakibatkan gangguan pertumbuhan janin, sehingga dibutuhkan pencegahan yang tepat untuk mengatasi anemia (Wiknjosastro, 2009).
Pencegahan dan pengobatan anemia menurut Fatmah (2011) dapat ditentukan dengan memperhatikan faktor-faktor penyebabnya, jika penyebabnya adalah masalah nutrisi, penilaian status gizi dibutuhkan untuk mengidentifikasi nutrient yang berperan dalam kasus anemia. Anemia gizi dapat disebabkan oleh berbagai macam nutrient penting pada pembentukan hemoglobin. Defisiensi Fe yang umum terjadi di dunia merupakan penyebab utama terjadinya anemia gizi, sehingga untuk mencegah defisiensi $\mathrm{Fe}$ diperlukan asupan zat besi dan makanan yang mengandung zat besi sesuai dengan kebutuhan seseorang.

Cara mengatasi kekurangan zat besi pada tubuh menurut Fatmah (2011) dengan cara mengkonsumsi $60-120 \mathrm{mg}$ Fe per hari dan meningkatkan asupan makanan sumber $\mathrm{Fe}$, selain itu menurut Wirakusumah (2007) untuk mengatasi anemia perlu konsumsi bahan-bahan pangan sumber zat besi, diantaranya daging, hati, ikan, susu, yoghurt, kacang-kacangan, serta sayuran berwarna hijau.

Salah satu jenis kacang-kacangan yang mengandung zat besi tinggi adalah kacang hijau. (vigna radiata). Kacang hijau sangat bermanfaat bagi kesehatan ibu hamil dan menyusui, juga untuk menunjang masa pertumbuhan anak (Akbar, 2015). Kandungan zat besi dalam kacang hijau paling banyak terdapat pada embrio dan kulit bijinya (Astawan, 2009) dengan jumlah kandungan zat besi pada kacang hijau sebanyak 6,7 mg per 100 gram kacang hijau dan salah satu bentuk penyajian kacang hijau yang paling efektif adalah 
dengan sari kacang hijau, yaitu air dan ampasnya disaring dan dipisahkan sehingga minuman tersebut padat gizi.

Penelitian tentang pemberian kacang hijau terhadap kadar hemoglobin pernah dilakukan oleh Negara (2015) yang dilakukan pada tikus putih dengan hasil ekstrak kacang hijau dapat meningkatkan kadar hemoglobin, sedangkan pada hasil penelitian Heltty (2008) menunjukkan bahwa pemberian jus kacang hijau dapat meningkatkan kadar hemoglobin dan sel darah pada pasien kanker dengan kemoterapi. Mengkonsumsi dua cangkir kacang hijau dalam setiap hari berarti telah mengkonsumsi $50 \%$ kebutuhan besi dalam setiap hari yaitu $18 \mathrm{mg}$ dan dapat meningkatkan kadar hemoglobin selama 2 minggu (Heltty, 2008)

Jumlah ibu hamil di Kabupaten Temanggung pada tahun 2015 sebanyak 6420 ibu hamil dengan 611 $(9,51 \%)$ ibu hamil mengalami anemia, sedangkan di wilayah kerja Puskesmas Pare Kabupaten Temanggung pada tahun 2015 sebanyak 310 ibu hamil dengan $22 \quad(7,096 \%)$ ibu hamil diantaranya mengalami anemia, lebih tinggi dari jumlah ibu hamil yang mengalami anemia di Puskesmas Kranggan yaitu dari 342 ibu hamil sebanyak 19 (5,5\%) ibu hamil yang mengalami anemia. Data pendahuluan yang diambil dari register pemeriksaan ibu hamil menunjukkan dari 8 orang ibu hamil dengan 4 ibu hamil mengalami anemia ringan dan 4 ibu hamil mengalami anemia sedang mengatakan bahwa selama ini ibu hanya mengkonsumsi tablet fe sesuai anjuran dari bidan, sedangkan pola makan selama ini hanya mengkonsumsi makanan berupa sayuran dan lauk yang sudah dimasak, sedangkan pemanfaatan kacang hijau hanya dikonsumsi ibu tidak rutin dalam bentuk bubur kacang hijau dan peyek kacang hijau, Hasil studi pendahuluan pada 12 ibu hamil diperoleh $58 \%$ ibu hamil mengkonsumsi kacang hijau dalam bentuk bubur sebanyak 1 bulan sekali pada saat mengikuti kegiatan posyandu, dan 25\% ibu hamil mengkonsumsi kacang hijau dalam bentuk rempeyek dan sisanya tidak menyukai kacang hijau.

Kacang hijau di wilayah Pare merupakan jenis kacang-kacangan yang mudah didapatkan di toko-toko maupun warung-warung kecil yang banyak dimanfaatkan masyarakat untuk membuat bubur kacang hijau, sedangkan pemanfaatan kacang hijau dalam bentuk lain adalah dengan dibuat rempeyek karena di wilayah Pare banyak industry rumah tangga kecil peyek kacang hijau.

Tujuan dari penelitian ini adalah untuk mengetahui pengaruh pemberian tablet Fe dan sari kacang hijau terhadap kadar hemoglobin pada ibu hamil.

\section{METODE PENELITIAN}

Penelitian ini merupakan bentuk penelitian kuantitatif dengan metode yang digunakan dalam penelitian ini adalah quasi experiment dengan desain Pretest-Postest Control Group Design. Tujuan dari penelitian ini adalah untuk menganalisis pengaruh pemberian tablet Fe dan sari kacang hijau terhadap kadar hemoglobin pada ibu hamil. Populasi penelitian ini adalah ibu hamil 
TM III di wilayah kerja Puskesmas Pare Kabupaten Temanggung dengan menggunakan teknik sampling total sampling yang terbagi menjadi 2 kelompok yaitu 32 ibu hamil kelompok intervensi dan 32 ibu hamil kelompok kontrol. Teknik pengumpulan data dilakukan adalah dengan menggunakan lembar observasi untuk mencatat hasil pengukuran kadar $\mathrm{Hb}$. Analisa data dengan menggunakan uji T-Test Independent dengan kepercayaan sebanyak $95 \%$.

\section{HASIL PENELITIAN}

Hasil penelitian menunjukkan ratarata kadar hemoglobin ibu hamil sebelum mendapatkan perlakuan pada kelompok intervensi adalah 9,8906 dan pada kelompok kontrol adalah 10,1063. Hasil penelitian tersebut menunjukkan bahwa kadar hemoglobin ibu masih di bawah normal (normal $11 \mathrm{gr} \%$ ), yang artinya ibu hamil mengalami anemia ringan.

\section{PEMBAHASAN}

Anemia menurut Tarwoto \& Wasnidar (2013) adalah kondisi dimana berkurangnya sel darah merah (eritrosit) dalam sirkulasi darah atau massa hemoglobin sehingga tidak mampu memenuhi fungsinya sebagai pembawa oksigen ke seluruh jaringan, sedangkan menurut Proverawati dan Asfuah (2009) anemia dalam kehamilan didefinisikan sebagai penurunan kadar hemoglobin kurang dari $11 \mathrm{~g} / \mathrm{dl}$ selama kehamilan pada trimester 1 dan ke-3, dan kurang dari $10 \mathrm{~g} / \mathrm{dl}$ selama post partum dan trimester 2.
Anemia pada kehamilan yang disebabkan kekurangan zat besi mencapai kurang lebih 95\%. Terjadinya peningkatan volume darah mengakibatkan hemodilusi atau pengenceran darah sehingga kadar $\mathrm{Hb}$ mengalami penurunan dan terjadi anemia. (Varney, 2007). Pengenceran darah dianggap sebagai penyesuaian diri secara fisiologis dalam kehamilan dan bermanfaat bagi wanita. Pertama tama pengenceran itu meringankan beban jantung yang harus bekerja lebih berat dalam masa hamil, karena sebagai akibat hidremia cardiac outputmeningkat (Saifuddin, 2006).

Hipervolemia yang diinduksi oleh kehamilan mempunyai beberapa fungsi penting antara lain : mengisi ruang vaskular di uterus, jaringan pembuluh di payudara, otot, ginjal dan kulit. Hipervolemia juga mengurangi efek pengeluaran hemogloblin pada persalinan. Penurunan kekentalan darah memperkecil resistensi terhadap aliran sehingga kerja jantung untuk mendorong darah menjadi lebih ringan. Faktor lain dari penyebab defisiensi $\mathrm{Fe}$ adalah meningkatnya kebutuhan $\mathrm{Fe}$ ibu hamil. Kebutuhan ibu hamil akan zat besi sebesar 900 mgr Fe, pada trimester dua (puncaknya usia kehamilan 32 sampai 34 minggu) akan terjadi hemodilusi (pengenceran darah) pada ibu hamil sehingga hemoglobin akan mengalami penurunan, mengakibatkan anemia kehamilan fisiologis.

Hasil penelitian menunjukkan ratarata kadar hemoglobin ibu hamil sesudah mendapatkan perlakuan pada kelompok intervensi adalah 10,7969 dan pada kelompok kontrol adalah 10,1250. 
Hasil penelitian menunjukkan bahwa kadar hemoglobin ibu hamil masih dibawah normal yang tergolong anemia ringan meskipun ada peningkatan pada keduanya. Pada kelompok intervensi terdapat peningkatan 0,9063 sedangkan pada kelompok kontrol hanya meningkat sedikit yaitu 0,0187 .

Peningkatan kadar hemoglobin pada kedua kelompok karena pada kedua kelompok tetap diberikan tablet Fe 60 gram yang menurut Saifuddin (2006) pemberian tablet $\mathrm{Fe} 60 \mathrm{mg} / \mathrm{hari}$ dapat menaikkan kadar hemoglobin sebanyak $1 \mathrm{gr} \%$ / bulan.

Penyebab anemia dalam kehamilan menurut Arisman (2010) adalah karena defisiensi zat besi, dan menurut Fatmah (2011) anemia gizi dapat disebabkan oleh kekurangan berbagai macam nutrient penting pada pembentukan hemoglobin. Defisiensi Fe yang umum terjadi di dunia merupakan penyebab utama terjadinya anemia gizi. Menurut Williams (2009), Kristiyanasari (2010) anemia dalam kehamilan dapat berdampak pada kesejahteraan ibu dan janin. Menurut Kemenkes (2015) anemia pada ibu hamil dihubungkan dengan meningkatnya kelahiran prematur, kematian ibu dan anak dan penyakit infeksi. Anemia defisiensi besi pada ibu hamil dapat mempengaruhi pertumbuhan dan perkembangan janin/bayi saat kehamilan maupun setelahnya.

Hasil uji analisis data dengan uji t-test dependent dengan hasil $p$ value pada kelompok intervensi adalah 0,000 yang artinya ada perbedaan kadar hemoglobin ibu hamil sebelum dan sesudah diberikan intervensi dan pada kelompok control dengan $p$ value 0,056 yang artinya tidak ada perbedaan kadar hemoglobin ibu hamil pada awal pemeriksaan dan pada akhir pemeriksaan kadar hemoglobin. Hasil penelitian ini menunjukkan bahwa setelah mengkonsumsi tablet fe dan kacang hijau kadar hemoglobin ibu hamil dapat meningkat dibandingkan dengan ibu hamil yang hanya mengkonsumsi tablet fe.

Salah satu cara mengatasi anemia dalam kehamilan menurut Wirakusumah (2007) ibu hamil perlu konsumsi bahanbahan pangan sumber zat besi, diantaranya daging, hati, ikan, susu, yoghurt, kacang-kacangan, serta sayuran berwarna hijau .

Salah satu jenis kacang-kacangan yang mengandung zat besi tinggi adalah kacang hijau. (vigna radiata). Kacang hijau sangat bermanfaat bagi kesehatan ibu hamil dan menyusui, juga untuk menunjang masa pertumbuhan anak (Akbar, 2015). Kandungan zat besi dalam kacang hijau paling banyak terdapat pada embrio dan kulit bijinya (Astawan, 2009) dengan jumlah kandungan zat besi pada kacang hijau sebanyak 6,7 mg per 100 gram kacang hijau dan salah satu bentuk penyajian kacang hijau yang paling efektif adalah dengan sari kacang hijau, yaitu air dan ampasnya disaring dan dipisahkan sehingga minuman tersebut padat gizi

Hasil uji analisis data dengan uji t-test independent dengan hasil $p$ value sebesar 0,000 yang artinya Ha diterima dan Ho ditolak, sehingga ada pengaruh pemberian tablet $\mathrm{Fe}$ dan sari kacang hijau terhadap kadar hemoglobin pada ibu hamil. 
Hasil penelitian ini sejalan dengan hasil penelitian Negara (2015) yang dilakukan pada tikus putih dengan hasil ekstrak kacang hijau dapat meningkatkan kadar hemoglobin, sedangkan pada hasil penelitian Heltty (2008) menunjukkan bahwa pemberian jus kacang hijau dapat meningkatkan kadar hemoglobin dan sel darah pada pasien kanker dengan kemoterapi. Mengkonsumsi dua cangkir kacang hijau dalam setiap hari berarti telah mengkonsumsi $50 \%$ kebutuhan besi dalam setiap hari yaitu $18 \mathrm{mg}$ dan dapat meningkatkan kadar hemoglobin selama 2 minggu (Heltty, 2008). Hasil penelitian Maulina (2010) juga menunjukkan pemberian kacang hijau selama 7 hari dapat meningkatkan kadar hemoglobin karena dalam hasil penelitiannya bahwa pemberian kacang hijau dosis 18 gr/kgBB/hari dan $36 \mathrm{gr} / \mathrm{kgBB} /$ hari efektif terhadap peningkatan kadar $\mathrm{Hb}$ pada tikus putih.

Pada wanita hamil dengan janin tunggal kebutuhan zat besi sekitar 1000 mg selama hamil atau naik sekitar 200$300 \%$. Perkiraan besarnya zat besi yang perlu ditimbun selama hamil 1040 mg. dari jumlah itu, $200 \mathrm{mg}$ zat besi tertahan oleh tubuh ketika melahirkan dan $840 \mathrm{mg}$ sisanya hilang. Sebanyak $300 \mathrm{mg}$ besi ditransfer ke janin dengan rincian 50-75 mg untuk pembentukan plasenta, $450 \mathrm{mg}$ untuk menambah jumlah sel darah merah dan 200 mg hilang ketika melahirkan.

Kebutuhan zat besi pada trimester pertama relatif lebih sedikit yaitu sekitar 0,8 mg per hari, tetapi pada trimester kedua dan trimester ketiga meningkat menjadi 6,3 mg per hari (Tarwoto \&
Wasnidar, 2013), sedangkan menurut Saifudin (2006) kebutuhan ibu selama kehamilan ialah $800 \mathrm{mg}$ besi, diantaranya $300 \mathrm{mg}$ untuk janin plasenta dan $500 \mathrm{mg}$ untuk pertambahan eritrosit ibu, dengan demikian ibu membutuhkan tambahan sekitar 2-3 mg besi/hari, dan menurut Jordan (2004) ibu hamil sejak berusia 20 minggu memerlukan zat besi $65 \mathrm{mg}$ per hari

Kacang hijau mengandung zat besi sebanyak 2,25 mg dalam setiap setengah cangkir kacang hijau. Kacang hijau juga mengandung fitat sebesar $2,19 \%$. Fitat dapat menghambat penyerapan zat besi sehingga dianjurkan untuk merendam kacang hijau sebelum mengolahnya. Pengolahan kacang hijau melalui perendaman sebelumnya bertujuan untuk memudahkan penyerapan zat besi yang diperlukan untuk maturasi selsel darah (Heltty, 2008)

Biji kacang hijau yang telah direbus atau diolah dan kemudian dikonsumsi mempunyai daya cerna yang tinggi dan rendah daya flatulensinya. Hemaglutinin dapat menggumpalkan sel darah merah dan bersifat toksik.

Toksisitas hemaglutinin dapat dihancurkan melalui proses pemanasan pada suhu $100^{\circ} \mathrm{C}$. Asam fitat dapat membentuk kompleks dengan $\mathrm{Fe}$ atau unsur-unsur mineral, terutama $\mathrm{Zn}, \mathrm{Mg}$, dan Ca menjadi bentuk yang tidak larut dan sulit diserap tubuh sehingga mengurangi ketersediannya dalam tubuh karena menjadi sangat sulit dicerna. Proses fermentasi dapat meningkatkan ketersediaan unsur besi bagi tubuh. Hal ini penting untuk mencegah anemia gizi besi (Astawan, 
2009). Kacang hijau juga mengandung vitamin $C$ yang membantu dalam melakukan penyerapan fe dalam tubuh karena dapat merubah bentuk feri menjadi fero.

\section{SIMPULAN}

Rata-rata kadar hemoglobin ibu hamil sebelum mendapatkan perlakuan pada kelompok intervensi adalah 9,8906 dan pada kelompok kontrol adalah 10,1063. Rata-rata kadar hemoglobin ibu hamil sesudah mendapatkan perlakuan pada kelompok intervensi adalah 10,7969 dan pada kelompok kontrol adalah 10,1250

Ada perbedaan kadar hemoglobin ibu hamil sebelum dan sesudah diberikan intervensi pada kelompok intervensi dengan $p$ value 0,000 dan pada kelompok control dengan $p$ value 0,056 .

Ada pengaruh pemberian tablet $\mathrm{Fe}$ dan sari kacang hijau terhadap kadar hemoglobin pada ibu hamil dengan $p$ value 0,000

\section{SARAN}

Ibu hamil disarankan untuk mengkonsumsi tablet $\mathrm{Fe}$ secara rutin dan dengan cara yang benar ditambah dengan mengkonsumsi sari kacang hijau karena merupakan salah satu sumber makanan yang dapat membantu meningkatkan kadar hemoglobin ibu hamil

Bidan dapat meningkatkan pelayanan kesehatan dengan memberikan penyuluhan pada ibu hamil pada saat kegiatan pelayanan antenatal care, posyandu dan kelas ibu hamil khususnya untuk mengatasi anemia pada ibu hamil dengan cara memberikan pendidikan kesehatan pada ibu hamil tentang manfaat kacang hijau sebagai salah satu bahan makanan yang dapat meningkatkan kadar hemoglobin ibu dan mencegah anemia

Peneliti lain diharapkan dapat melakukan penelitian lanjutan tentang peningkatan kadar haemoglobin dengan menggunakan kacang hijau dengan sampel yang lebih banyak serta menggali faktor-faktor lain yang mempengaruhi terjadinya anemia pada ibu hamil antara lain faktor yang menghambat dan membantu penyerapan zat besi, seperti cara minum tablet $\mathrm{Fe}$, umur, paritas dan jenis makanan yang dikonsumsi ibu hamil, selain itu juga jangka waktu yang lebih lama untuk pemberian intervensi agar dapat mengidentifikasi signifikansi peningkatan kadar hemoglobin

\section{DAFTAR PUSTAKA}

Akbar. 2015. Aneka Tanaman Apotek Hidup di Sekitar Kita. Jakarta : One Book.

Almatzier. (2004). Prinsip Dasar IImu Gizi. Jakarta : Gramedia.

Arisman. 2010. Gizi dalam Daur Kehidupan. Jakarta : EGC.

Astawan. 2009. Sehat dengan Hidangan Kacang dan Biji-Bijian. Jakarta : Penebar Swadaya

Astuti. 2015. Pengaruh konsumsi jus bayam merah terhadap peningkatan kadar Hb lbu Hamil di kecamatan Tawangmangu. Surakarta : Politeknik Kesehatan Kemenkes Surakarta.

Cunningham. 2005. Obstetri Williams. Jakarta : EGC 
Dinas Kesehatan Jawa Tengah. 2013. Profil Kesehatan Propinsi Jawa Tengah 2012. Semarang: Dinas Kesehatan Jawa Tengah.

Fatmah. 2011. Gizi dan Kesehatan Masyarakat: Anemia. Jakarta: PT. Raja Grafindo Persada.

Guyton AC. 2007. Fisiologi Manusia dan Mekanisme Penyakit. Jakarta: Penerbit Buku Kedokteran EGC. Alih bahasa oleh Dr. Petrus Andrianto

Heltty. 2008. Pengaruh Jus Kacang Hijau Terhadap Kadar Hemoglobin dan Jumlah Sel Darah dalam Konteks Asuhan Keperawatan Pasien Kanker dengan Kemoterapi di RSUP Fatmawati Jakarta. Tesis. Jakarta : UI

James, Dkk. 2008. Prinsip-prinsip Sains untuk Keperawatan, Alih Bahasa Wardhani. Jakarta : Erlangga

Jordan. 2004. Farmakologi Kebidanan. Jakarta : EGC

Kemenkes RI. 2015. Infodatin : Pusat Data dan Informasi Kementerian Kesehatan RI. Jakarta: Kemenkes RI.

Kristiyanasari. 2010. Gizi Ibu Hamil. Yogyakarta : Nuha Medika.

Kusmiyati dan Wahyuningsih. (2015). Asuhan Ibu Hamil. Yogyakarta : Fitramaya

Manuaba. 2009. Memahami Kesehatan Reproduksi Wanita. Jakarta : EGC.

Maulina.2010. Pengaruh Pemberian Kacang Hijau (Phaseolus radiatus) Terhadap Peningkatan Kadar Hemoglobin Tikus Putih (Rattus norvegicus) Jantan Galur Wistar.
Aceh : Jurnal Fakultas Kedokteran Universitas Malukusaleh.

Nagara. 2015. Pemberian Campuran Ekstrak Kacang Hijau (Phaseolus radiatus) dan Ekstrak Pepaya (Carica papaya L) Meningkatkan Kadar Hemoglobin Darah Tikus Putih. http://ejournal.undiksha.ac.id/index.p hp/JJPB/article/view/5877.

Notoatmodjo. 2010. Metode Penelitian Kesehatan. Jakarta : Rineka Cipta

Nuraysih. 2015. Efektivitas Terapi Kombinasi Jus Bayam-Jeruk SunkisMadu terhadap Kadar Hemoglobin pada Ibu Hamil dengan Anemia di Wilayah Kerja UPTD Puskesmas Kecamatan Pontianak Selatan. Pontianak : Universitas Tanjungpura.

Proverawati dan Asfuah. (2009). Gizi untuk Kebidanan. Jakarta : Nuha Medika.

Riskesdas. 2013. Riset Kesehatan Dasar Indonesia Tahun 2013. Jakarta : Kemenkes RI.

Rukiyah. 2009. Asuhan Kebidanan 1 (Kehamilan). Jakarta : TIM.

Rusilanti dan Kusharto. 2007. Sehat dengan Makanan Berserat. Jakarta : Agromedia Pustaka.

Susilaningtyas. 2013. Pemberian Zat Besi (Fe) dalam Kehamilan. Semarang : UNISULA

Saifuddin. 2006. Buku Acuan Nasional Pelayanan Kesehatan Maternal dan Neonatal. Jakarta : YBP-SP.

Sulistyawati. (2009). Asuhan Kebidanan pada Masa Kehamilan. Jakarta : Salemba Medika. 
Supariasa. 2012. Penilaian Status Gizi. Jakarta : EGC.

Tarwoto dan Wasnidar. 2013. Buku Saku Anemia pada Ibu Hamil : Konsep dan Penatalaksanaannya. Jakarta : Trans Info Media.

Tjay dan Rahardja. 2013. Obat-Obat Penting. Jakarta : Elex Media Komputindo

Varney. 2007. Buku Ajar Asuhan Kebidanan Volume 1. Jakarta : EGC.

Wiknjosastro. 2006. Ilmu Kebidanan. Jakarta : Bina Pustaka Sarwono Prawirohardjo.

Wiknjosastro. 2009. IImu Kebidanan. Jakarta : Bina Pustaka Sarwono Prawirohardjo.

Wirakusumah. 2007. 202 Jus Buah \& Sayuran Untuk Menjaga Kesehatan dan Kebugaran Anda. Jakarta : Penebar Plus.

Zen. 2013. Pengaruh Pemberian Sari Kurma (Phoenix dactylifera) terhadap Kadar Hemoglobin. Studi Eksperimental pada Tikus Putih Jantan Galur Wistar yang Diberi Diet Rendah Zat Besi (Fe). Sains Medika,Vol. 5, No. 1, Januari - Juni $2013: 17-19$ 